\section{Ophthalmic anaesthesia}

Chandra Kumar, Chris Dodds, Gary Fanning (Editors). Swets \& Zeitlinger Publishers, Q1The Netherlands, 2002, $£ 195$, EUR 89,00, US\$ 89.00, ISBN 902651928 1, 226 pp

Eye (2004) 18, 113. doi:10.1038/ sj.eye. 6700539

The editors have put together contributions from a team of eminent ophthalmologists and anaesthesiologists to compile this work. Many of the contributors are members of The Ophthalmic Anesthesia Society (OAS) and The British Ophthalmic Anaesthesia Society (BOAS). Thus, the views expressed reflect practice on both sides of the Atlantic, which, especially in this field can be quite divergent. The differing viewpoints are balanced well and definitely enhance the value of this book. The reader is left to make up his own mind on the various debates in this field, for example, general vs local; deep sedation $v s$ minimal or no sedation, etc.

All aspects of ophthalmic anaesthesia from topical to general are well covered. Extensive reference list at the end of each chapter guides the interested reader to delve further into areas of interest to them. Both theoretical and practical aspects are well discussed. I strongly recommend this book as an important addition to departmental libraries, both anaesthetic and ophthalmic. Most anaesthesiologists who wish to develop an interest in ophthalmic anaesthesia will find it an essential read, many ophthalmologists will benefit from accruing a better understanding of how the 'other side' works and will therefore be able to develop a better interaction with their anaesthesiologist colleagues.

Some parts of the book are outright disturbing. The chapter on highvolume cataract surgery outlines ways in which high-volume surgery can be streamlined; it advocates rates of 10-15 cataract operations ....wait for it ... per hour. Some passages from the concluding chapter 'A vision of the future' immediately reminded me of Aldous Huxley's 'Brave New World'. But then, if a book does not challenge you enough to disturb you, maybe it is missing its point!

S Prasad Consultant Ophthalmologist Arrowe Park Hospital, Wirral, UK 